\title{
Quantifying methane emissions from Queensland's coal seam gas producing Surat Basin using inventory data and an efficient regional 5 Bayesian inversion
}

Ashok K. Luhar et al.

Correspondence to: Ashok K. Luhar (ashok.luhar@csiro.au)

\section{Table of contents}

10 S1. Data filtering

S2. Bottom-up methane emission inventory

S3. Estimating the background methane concentration

S4. Model performance for meteorology

Figures S1 to S3

15 References

\section{S1. Data filtering}

\section{S1.1 Filtering for nearby cattle}

Our standard data processing, using the software package GCWerks (http://www.gcwerks.com/), involves manual checks on a number of instrument parameters, but also some automatic flagging procedures based on very conservative thresholds for removing spurious data. In particular, GCWerks removes outlying points in the high frequency data if they lie more than 10 standard deviations from the mean, as calculated over a two-minute moving average window. By judiciously modifying the default parameters in the GCWerks' statistical filter, we are able to remove the signal due to the local cattle, without modifying the underlying signal from more distant sources. We find the optimal filter parameters for filtering nearby cattle signal to be a standard deviation of 2.5 , with a moving average over a ten-minute window.

25 To give an example, Figure $\mathrm{S} 1$ shows the measured time series of minutely mean $\mathrm{CO}_{2}, \mathrm{CH}_{4}$ and $\mathrm{CO}$ at Burncluith for 10 January 2017. Particularly from 0100-0900 UTC (1100-1900 AEST), there is a series of sharp spikes in the $\mathrm{CH}_{4}$ record. At this time, there were light winds from an east-south-easterly direction, and the landholder confirmed that there were cows 
loitering to the east of the intake line. While the 'tight' or cattle filter removes most of these sharp peaks in the minutely data, it retains the underlying rise in $\mathrm{CH}_{4}$ between 0400 and 0600 UTC which mirrors the rise in CO, suggestive of biomass

burning signal being transported from further afield.

The same cattle filter was applied to the Ironbark data, for consistency, although cattle are fewer and further away at Ironbark and have much less impact on the methane measurements.

\section{S1.2 Diurnal and low wind filtering}

Nocturnal low wind conditions can be approximately defined as those with a wind speed at 10-m above ground of less than

$352-3 \mathrm{~m} \mathrm{~s}^{-1}$, which corresponds to a Richardson number (a stability parameter that is the ratio of buoyant suppression of turbulence to shear generation of turbulence in the lower atmosphere) greater than $0.2-0.3$ (Luhar et al., 2009). There are considerable occurrences of high methane concentrations at the two sites under such conditions. This is mostly because under these conditions the atmosphere near the ground is typically characterised by strong stable stratification with a very shallow inversion layer so that even small local sources near the ground can lead to very large enhancements in the local methane concentration due to very little vertical atmospheric mixing. Despite being of considerable practical interest, however, these are some of the most difficult conditions to simulate by a flow and dispersion model, particularly at a regional or mesoscale. Thus, one option to circumvent the issue of modelling generally not being able to properly simulate strong inversion conditions at night is to consider daytime hours (1000-1700 h) irrespective of wind speed, and the remaining hours for which the wind speed is greater than $3 \mathrm{~m} \mathrm{~s}^{-1}$. The daytime window typically corresponds to periods of strong mixing dominated by convective motions resulting from the solar heating of the ground. For data selection for the two sites, the respective measured wind speeds were used.

\section{S1.3 Filtering for biomass burning events}

Both methane and $\mathrm{CO}$ are emitted from biomass burning. $\mathrm{CO}$ is not present in other large methane sources of interest, including those compiled in the bottom-up emissions inventory. Methane emissions from power stations, domestic wood heating and vehicles on the other hand would contain $\mathrm{CO}$, but the modelled $\mathrm{CH}_{4}$ signals for these sources are predicted to be virtually undetectable at Burncluith. The majority (89\%) of CSG methane source emissions in the bottom-up inventory are not from combustion. Importantly, emissions from the less well known migratory or seepage sources, which also do not originate from combustion, would not be screened out by a $\mathrm{CO}$ filter. Thus, comparisons of observed $\mathrm{CH}_{4}$ with model simulations are more accurately made by excluding hourly periods with large $\mathrm{CO}$ enhancements above the background $\mathrm{CO}$ concentration.

A plot of the measured $\mathrm{CO}$ vs $\mathrm{CH}_{4}$ concentrations at Burncluith after applying the above cattle and low wind filtering is shown in in Figure S2 (orange circles). Two distinct groupings are apparent; the data group with high magnitudes of CO concentration likely represents dominant contributions from combustion sources. Enhancements of $\mathrm{CO}$ above background at 
Burncluith are mostly observed during north-westerly and easterly winds, consistent with the locations of the occasional

60 forest burn offs and the wood fire in the dwelling adjacent to the monitoring station, respectively. (The background CO concentration was calculated using the same methodology as the background $\mathrm{CH}_{4}$ (Section 4.2). To filter out such events, we chose an hourly mean $\mathrm{CO}$ enhancement of $10 \mathrm{ppb}$ (above the background) as a cut off, which is about twice the one standard-deviation uncertainty in the observed $\mathrm{CO}$ around the estimated background $\mathrm{CO}$ variation without considering the $\mathrm{CO}$ enhancement periods. The hourly mean data points after removing the data points with $\mathrm{CO}$ values greater than $10 \mathrm{ppb}$

65 above background concentrations are shown as blue dots in Figure S2. This CO filter further removed about $22 \%$ of the filtered Burncluith data.

\section{S2. Bottom-up methane emission inventory}

The following is a brief account of how the bottom-up methane emissions from the various sectors for the year 2015 were compiled. Full details are given in a report by Katestone (2018).

\section{$70 \quad$ S2.1 Grazing cattle}

The information used to estimate methane emissions for grazing cattle included:

- Total cattle livestock and grazing area based on agricultural commodities for Australia for 2014-15 (ABS, 2015a) and Land Management and Farming in Australia for 2014-15 (ABS, 2015b).

- Digital Boundaries for National Resource Management (NRM Regions) for 2016 (DEE, 2016).

- Methane emission factor for grazing cattle based on direct measurements (Harper et al., 1999).

The number of grazing cattle were calculated in each NRM region and was distributed uniformly across the region. This was then multiplied by the emission factor to give the corresponding methane emissions. There were 1,086,059 grazing cattle in the study area.

\section{S2.2 Feedlots}

80 The following information was used to compute methane emissions for cattle in feedlots:

- National Pollutant Inventory (NPI) data for the 2014/15 reporting year with the ANZSIC (Australian and New Zealand Standard Industrial Classification) description "Beef Cattle Feedlots (Specialised)".

- Queensland Government datasets including Lot and plan boundaries (Property boundaries Queensland cadastral dataset) and Locations and standard cattle unit numbers contained in NRM regions (Department of Agriculture and Fisheries). 
- Methane emission factor for "enteric fermentation" and "manure management" for non-dairy cattle from the Food and Agriculture Organization (FAO) of the United Nations (FAOSTAT, 2016). A total emission factor combines the above two methane sources at a feedlot.

There were 235 cattle feedlots in the study area. The number of cattle per feedlot was estimated. The methane emissions

were calculated by multiplying the number of cattle per feedlot by the emission factor.

\section{S2.3 Coal Seam Gas (CSG) activities}

The locations of CSG wells and processing facilities were based on data available through DNRM and methane emissions data and calculations were provided by the operators.

The information used to calculate the CSG methane emissions included: locations of CSG wells and processing facilities, methane emissions data and reporting prepared for the National Greenhouse and Energy Reporting (NGER) program and directly from the operators, quantity of gas combusted and the volume of produced water.

The calculation methods are consistent with the NGER program where methane is classified as a greenhouse gas and is quantified and reported in terms of carbon dioxide equivalents.

Combustion: Emissions of methane due to combustion of CSG (including flaring) and diesel were calculated as the product

100 of the quantity of fuel type, the energy content of fuel type, an appropriated emission factor and the GWP of methane.

Fugitive emissions (venting of CSG): Estimates of the quantities of gas vented are based on methods prescribed by the Compendium of Greenhouse Gas Emissions Methodologies for the Oil and Natural Gas Industry (API Compendium) (API, 2009). Emissions were estimated based on the direct measurement of gas released, if this information was unavailable industry standard factors were applied (API, 2009).

105 Fugitive emissions (other than venting or flaring): These fugitive methane emissions include emissions from (NGER Determination 2008, Section 3.70 (Clean Energy Regulator, 2016)): a gas wellhead through to the inlet of a gas processing plant, a gas wellhead through to the tie-in points on gas transmission systems (if processing of natural gas is not required), gas processing plants, well servicing, gas gathering, gas processing and associated waste water disposal. The emissions are calculated as the product of the total quantity of natural gas, the appropriate emission factor and the GWP of methane.

\section{$110 \quad$ S2.4 Coal mining}

Methane emissions for four coal mines in the study were calculated from the following information (only the dominant coal extraction process was included):

- Run of Mine (ROM) (gross raw output) coal tonnages for 2014/15 (Department of Natural Resources and Mines (DNRM) - Queensland coal production by individual mine, May 2016). 
- DNRM Mining lease surface areas.

- Fugitive methane emission factor for extraction of coal in Queensland of 0.02 tonnes $\mathrm{CO}_{2}$-e per tonne of raw coal (DoE, 2016).

- $\quad$ Methane Global Warming Potential (GWP) of 25 (DoE, 2016).

The methane emissions for each mine were calculated by multiplying the amount of ROM coal by the appropriate emission

factor. They were allocated uniformly across the mining lease areas associated with each mine as identified from the DNRM dataset.

\section{S3. Estimating the background methane concentration}

Data from the measured concentration time series were retained if they occurred between $1200-1500 \mathrm{~h}$ local time (typically the time of highest boundary layer height and maximum trace gas homogeneity during the diurnal cycle) and the hourly standard deviation of concentration was less than or equal to $1 \mathrm{ppb}$, indicating very well mixed conditions. This filtered dataset was then used to derive a smooth curve. Based on the method described by Thoning et al. (1989), the filtered dataset was fitted with a function consisting of a cubic polynomial and three harmonics. This fit is then subtracted from the filtered data and the residuals further filtered with a band-pass filter of 80 days. The original function fit is then added back to the filtered residuals to give a smooth fit through the data. These operations are performed iteratively (with hours lying outside twice the standard deviation around the fit excluded) until the fit converges. An interpolation routine then produced the fitted background $\mathrm{CH}_{4}$ concentrations at each of the hourly timestamps of the original measured data.

\section{S4. Model performance for meteorology}

In Figure S3, the modelled winds are qualitatively similar to those observed, with the most frequent modelled wind direction also from the north-east quadrant, and winds from the south-west quadrant modelled at a relatively smaller frequency in

135 agreement with the observations. The modelled winds at Burncluith and Ironbark are more similar than those observed. At Burncluith the model underestimates the frequency of low wind speed events $\left(<2 \mathrm{~m} \mathrm{~s}^{-1}\right)$, which mostly occurs at night, and overestimates the frequency of higher wind speed events $\left(>4 \mathrm{~m} \mathrm{~s}^{-1}\right)$ from the north-east sector. The wind speed distribution at Ironbark is better modelled than that at Burncluith—one reason for this could be that Burncluith has several tall trees in the vicinity which may weaken the flow field and whose influence is not properly accounted for in the model. There is also a

140 difference in the height at which winds are given: the model height is $10 \mathrm{~m}$ whereas, it is $7.6 \mathrm{~m}$ at Burncluith and $5.8 \mathrm{~m}$ at Ironbark. Generally, in the surface layer, winds get stronger with height, and, therefore, one factor in the modelled winds being stronger than the observation could be the height difference. 
We also calculated commonly used model performance statistics, but it is not feasible to present a comprehensive meteorological evaluation of the model here, except to report that the overall model-data correlation coefficient $(r)$ for wind 145 speed at Ironbark was 0.68 and it was 0.66 at Burncluith. Another parameter, the Index of Agreement (IOA, $=0$ no agreement, = 1 perfect agreement), which, unlike the correlation coefficient, is sensitive to differences between the observed and model means as well as to certain changes in proportionality (Willmott, 1981) was 0.82 for Ironbark and 0.76 for Burncluith. As judged from the IOA values, the overall TAPM performance for winds for the Surat Basin is satisfactory and comparable to those in other studies (e.g., Luhar and Hurley, 2003; Hurley et al., 2005) (also see papers in TAPM citation 150 database https://scholar.google.com.au/scholar?oi=bibs\&hl=en\&cites=13876071272134760358). 

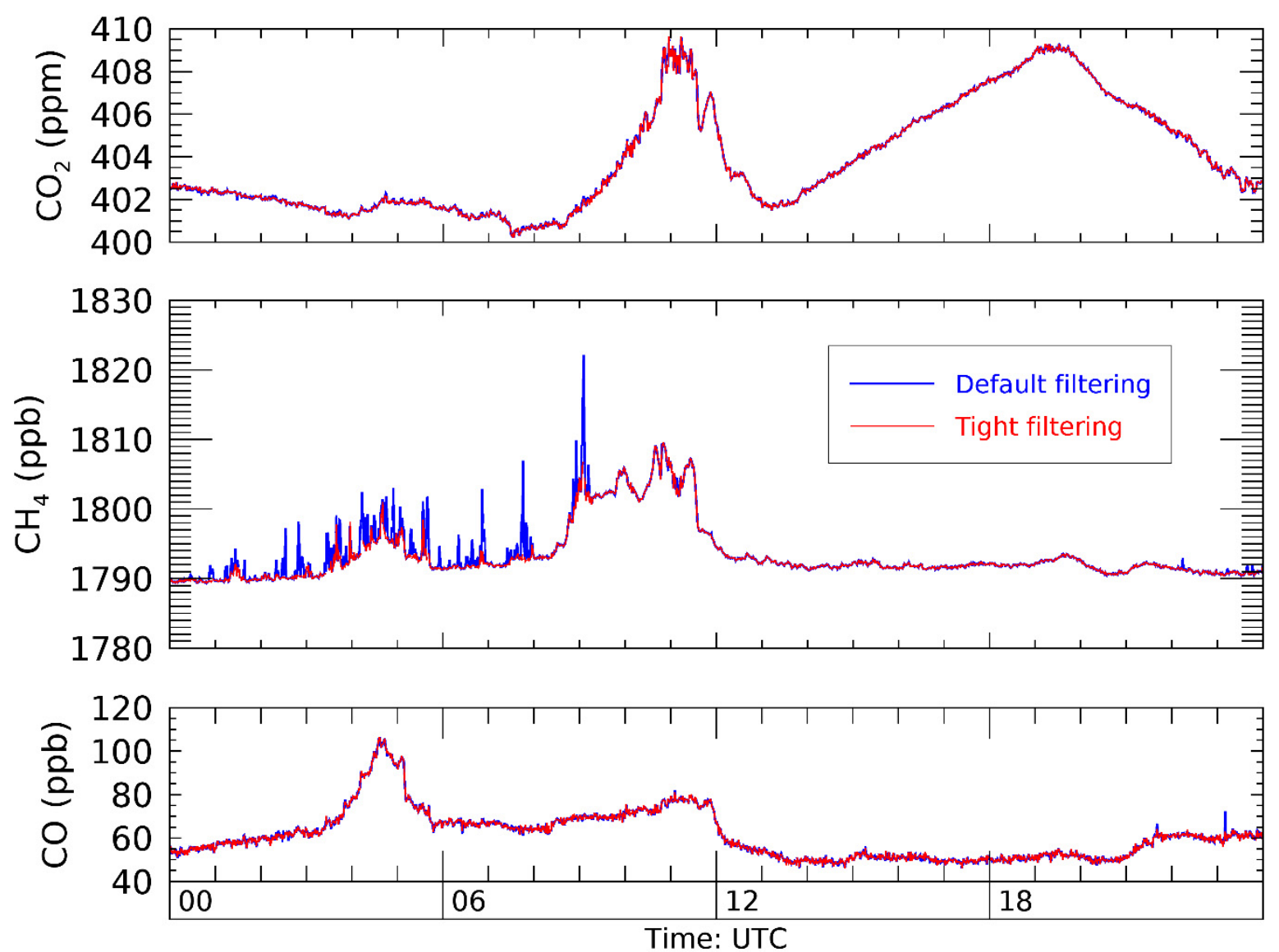

Figure S1. Burncluith minutely-mean data for 10 January 2017. Blue curve represents the default filtering, red curve the cow filtering ("tight"). Where the two curves cannot be seen separately, they overlap. 


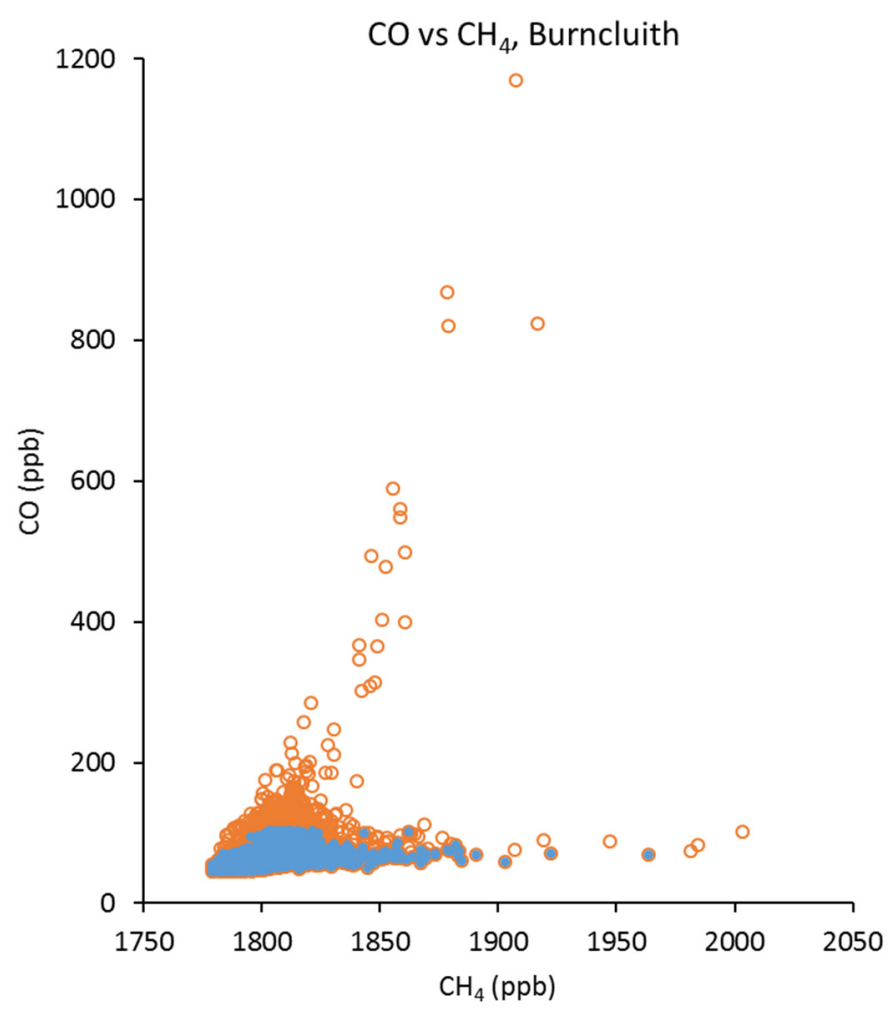

160 Figure S2. Hourly mean concentrations of $\mathrm{CO}$ versus $\mathrm{CH}_{4}$ measured at Burncluith selected for $1000-1700$ for all wind speeds and for 1800-0900 for wind speed greater than $3 \mathrm{~m} \mathrm{~s}^{-1}$ (orange circles). The data group with high magnitudes of CO concentration likely represents dominant contributions from combustion sources. The data marked with blue dots are the measurements when hourly mean $\mathrm{CO}$ concentrations are within $10 \mathrm{ppb}$ of the background CO concentration at the time of measurement and are selected to represent contributions from non-combustion sources. 


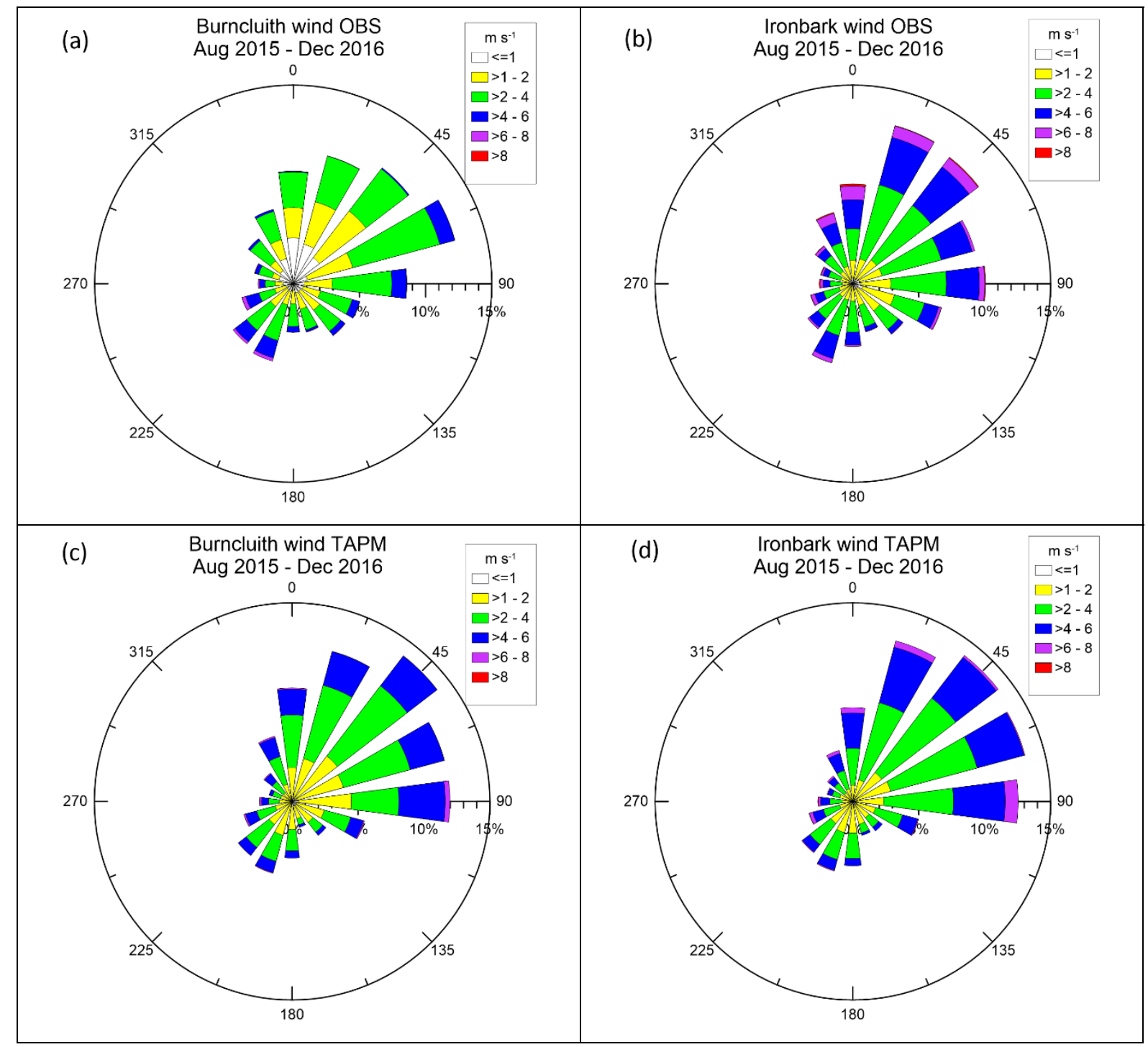

Figure S3. Observed $(\mathrm{a}, \mathrm{b})$ and modelled $(\mathrm{c}, \mathrm{d})$ wind roses for the Burncluith and Ironbark monitoring sites. 


\section{References}

ABS (Australian Bureau of Statistics): Agricultural Commodities. Available at http://www.abs.gov.au/AUSSTATS/abs@.nsf/DetailsPage/7121.02014-15?OpenDocument, 2015a.

ABS (Australian Bureau of Statistics): Land Management and Farming in Australia. http://www.abs.gov.au/AUSSTATS/abs@.nsf/DetailsPage/4627.02014-15?OpenDocument,2015b.

API (American Petroleum Institute): Compendium of Greenhouse Gas Emissions Methodologies for the Oil and Natural Gas

175 Industry Available at: www.api.org, 2009.

Clean Energy Regulator: National Greenhouse and Energy Reporting (Measurement) Determination 2008. Australian Government, 2016a.

DEE (Department of the Environment and Energy): Natural Resource Management (NRM) Regions for 2016. Available at http://www.environment.gov.au/fed/catalog/search/resource/details.page?uuid=\%7BAB80DA43-CB00-455D-8A3C-

$180 \quad$ 70162EB8D964\%7D, 2016.

Department of Natural Resources and Mines (NRM): Key resource areas - resource processing area - Queensland. State of Queensland (Department of Natural Resources and Mines). Published 17 April 2015. Available at http://qldspatial.information.qld.gov.au/catalogue/, 2015.

Department of the Environment (DoE): National Greenhouse Accounts Factors, Australian National Greenhouse Accounts,

185 August 2016, Australian Government Department of the Environment, ISSN: 2202-333X, 2016.

FAOSTAT: Food and Agriculture Organization of the United Nations. Available at http://fenix.fao.org/faostat/beta/en/\#data/GE, 2016.

Harper, L. A, Denmead, O. T., Freney, J. R, and Byers, F. M.: Direct measurements of methane emissions from grazing and feedlot cattle, Journal of Animal Science, 77(6), 1392-1401, https://doi.org/10.2527/1999.7761392x, 1999.

190 Hurley, P. J., Physick, W. L., and Luhar, A. K.: TAPM: a practical approach to prognostic meteorological and air pollution modelling, Environmental Modelling and Software, 20(6), 737-752, https://doi.org/10.1016/j.envsoft.2004.04.006, 2005.

Katestone: Surat Basin Methane Inventory 2015 - Summary Report. Prepared by Katestone Environmental Pty Ltd, Brisbane, Queensland, for CSIRO, document no. D15193-18, 2018.

Luhar, A. K. and Hurley, P.: Evaluation of TAPM, a prognostic meteorological and air pollution model, using urban and 195 rural point source data, Atmospheric Environment, 37(20), 2795-2810, https://doi.org/10.1016/S1352-2310(03)00204-8, 2003.

Luhar, A. K., Hurley, P. J., and Rayner, K. N.: Modelling near-surface low winds over land under stable conditions: Sensitivity tests, flux-gradient relationships, and stability parameters, Boundary-Layer Meteorology, 130(2), 249-274, https://doi.org/10.1007/s10546-008-9341-7, 2009. 
200 Thoning, K. W., Tans, P. P., and Komhyr, W. D.: Atmospheric Carbon Dioxide at Mauna Loa Observatory: 2. Analysis of the NOAA GMCC Data, 1974-1985, Journal of Geophysical Research: Atmospheres, 94(D6), 8549-8565, https://doi.org/10.1029/JD094iD06p08549, 1989.

Willmott, C. J.: On the validation of models, Physical Geography, 2(2), 184-194, https://doi.org/10.1080/02723646.1981.10642213, 1981. 